\title{
REPATRIATION OF RHODODENDRON PLANTS TO CHINA
}

\author{
David Paterson
}

\begin{abstract}
A Darwin Initiative grant awarded to the Royal Botanic Garden Edinburgh in 1994 gave the opportunity to train some Chinese horticulturists and repatriate a number of rhododendrons back to China from the Garden in Edinburgh. The Chinese partners in the programme were Hua Xi Alpine Botanic Garden and Guizhou Botanic Garden. The initial stages of the project involved training and the selection of suitable species. Following some trials and discussion about possible genetic contamination of native populations from imported material, work on propagating the plants started. Once rooted the plants were packed and transported to China. Following site preparation the young plants were planted in nursery beds. Two hundred and thirty plants, representing almost 100 species, were planted. Of these more than $80 \%$ established successfully. Seed was also collected in China from small populations of endemic species of rhododendron to include in the project. The final stage of the project involved help with garden design at Hua Xi.
\end{abstract}

\section{INTRODUCTION}

In 1994 the Royal Botanic Garden Edinburgh (RBGE) was awarded a Darwin Initiative grant to facilitate the training of young Chinese horticulturists and to allow the repatriation of a number of rhododendron species to China. The Chinese partners in this programme were Hua Xi Sub Alpine Botanic Garden (now the West China Rhododendron Garden) and the Guizhou Botanic Garden. Hua Xi Sub Alpine Botanic Garden is located in Sichuan Province in southwest China on the wet, western flanks of the Hungduan Shan. The nearest conurbation to the Garden is the town of Dujiang Yen which is situated to the extreme west of the Sichuan basin and has built up along the banks of the Min River. The nearest city is Chengdu, the provincial capital of Sichuan, which is less than $100 \mathrm{~km}$ from the Garden. Guizhou Botanic Garden is located on the outskirts of Guiyang, the provincial capital of Guizhou Province.

A number of RBGE staff were involved in the project. Dr David Chamberlain, the recipient of the Darwin Initiative award, provided scientific input into the project. Garden Supervisors Tony Garn and Peter Brownless provided much of the horticultural training. David Paterson, the Curator of the Gardens Department and responsible for the Rhododendron collection, co-ordinated the training and repatriation programmes.

David Paterson is the Deputy Director of Horticulture and Curator of the Gardens Department at the Royal Botanic Garden Edinburgh. 


\section{Training Programme}

The training programme for the Chinese horticulturists involved both in situ assessment of facilities and skills within their own gardens and the provision of specialist coaching using the Living Collections and resources at RBGE. The objective of the training was to allow students to develop a range of specialist growing skills. This would enable them to care successfully for the repatriated plants, but would also enable them to initiate stabilisation programmes that would attempt to halt the decline of vulnerable rhododendron species from their respective parts of southwest China. The preferred method of training was through a year-long intensive programme of practical instruction backed up, where necessary, with more formal classroom-based sessions covering the theory and principles of good horticultural practice. This model was agreed by Professor Chen Minghong, Director of Hua Xi Sub Alpine Botanic Garden, and put into practice in 1994 when their representative, Miss Geng Yuying, an Associate Professor of the Chinese Academy of Sciences, was sent to Edinburgh to undertake the training programme. Unfortunately, despite agreeing to the training model in principle, staff from Guizhou Botanic Garden were unable to follow the programme for a number of reasons. Significantly though, this had an effect on the success of their part of the project and highlights the need for good training programmes in projects of this type.

The training programme started in the autumn of 1994 and, in the early stages, focused mainly on soil husbandry. Both of the Chinese gardens involved in the scheme intended to develop extensive living collections of species rhododendrons and were planning to display them in an attractive landscape setting. It was clear from the outset, therefore, that the training in aspects of landscape design and management would also be essential. With this in mind, the winter months of Miss Geng's year in Edinburgh were spent working alongside the RBGE horticultural team on the development of the Chinese Hillside, a new landscape containing a range of habitats for the cultivation of Chinese plants. An emphasis was placed on teaching the fundamentals of landscape construction and on the use of hand tools and machinery commonly employed in such developments. From this very practical foundation, the focus of training then moved towards plant propagation and production, before eventually closing the circle by dealing with the planting of various categories of nursery stock.

\section{Repatriation Programme}

While this practical training was taking place the process of identifying suitable species of rhododendron for repatriation to Sichuan Province began. The acquisitions policy for Hua Xi Sub Alpine Botanic Garden had been developed to deal with native and endemic species from the wet, western flanks of the Hengduan Shan. The primary objective of the policy was the conservation, through horticultural intervention, of a number of Chinese Red Data Book plants that grow in the alpine and 
subalpine zones of mountains such as Zheguo Shan, Omei Shan, Balang Shan and other peaks of the Hengduan Shan range. Foremost within the range of genera targeted by the policy was Rhododendron, but included also were Davidia, Cercidiphyllum, Magnolia, Michelia and herbaceous taxa in genera such as Primula, Meconopsis and Cardiocrinum. With the existence of such a well-developed acquisition policy at RBGE, it was not too difficult to identify a range of suitable Rhododendron species for possible repatriation. The most appropriate species for repatriation to Sichuan Province from within RBGE's collections were those that had their origins in the province. Some discussion took place concerning possible contamination of the existing populations of rhododendrons that grow on the slopes above Hua Xi Garden through the introduction of species, or from germplasm of plants that may have been collected from other parts of their range. Despite the generally excellent quality of record keeping at RBGE it was, however, impossible to say with absolute certainty that all the plants identified for repatriation were originally collected from the Dujiang Yen Prefecture of Sichuan Province. From basic investigative research carried out it seemed unlikely that there would be sufficient plant material of the calibre required within the RBGE collections to make the programme worthwhile if regulations were to be so restrictive. However, when it became clear that the slopes around Hua Xi were anything but pristine, it was felt that the inclusion of germplasm from other parts of a species' range would have little, if any, impact on the sparse existing populations. Furthermore, all repatriated plants were destined for the Garden site, which is remote from the natural slopes by virtue of tourist developments along the valley floor of the Long Xi Reserve, within which Hua Xi Garden is located. The likelihood, therefore, of cultivated material escaping into the wild was deemed to be low.

The list of species for eventual repatriation was finalised and work started on propagating the plants. All the plants were raised vegetatively, mostly by semi-ripe wood cuttings. Since all plants had to be root washed to comply with phytosanitary regulations, the rooted cuttings were grown in an open medium. The aim was to stimulate the production of fibrous root growth in a medium that could be easily washed off without damaging, or significantly reducing, the root mass. Because some of the plants had already been grown prior to the start of the project, there was a range of material to work with, from one-year-old rooted cuttings to four-year-old established shrubs. Some early trials involving root washing had shown that the youngest plants retained a greater percentage of their original root mass. However, the propagation team expressed concerns about the robustness of the one-year-old rooted cuttings and indeed most of the losses incurred during the repatriation process involved these plants. A decision was also made not to reduce the leaf area index through leaf removal or cutting the leaves in half. Some trials were carried out on the use of antidessicants, both around the roots and over the foliage. The trials proved inconclusive and a decision was reached not to use such materials. Instead, the roots were placed in a water-soaked inert media of vermiculite. Each plant was then sealed individually in a polythene bag and the bags were then packed loosely 
into cardboard boxes and protected from damage using polystyrene beads. It was anticipated that the polystyrene would also insulate against temperature fluctuations during transit.

There was much debate about the optimum timing for the repatriation of the material since the weather conditions immediately after planting would have a significant effect on the successful establishment of the plants. The advantage of repatriation during the early spring months was mainly identified as the initiation of early post planting root growth but the major concern was the high early summer temperatures occasionally experienced at Hua Xi Sub Alpine Botanic Garden. It was therefore agreed that the repatriation exercise should be carried out during the autumn months when the soil moisture content would be at or near field capacity and evapotranspiration from the leaf surface would be low due to the cool damp conditions.

Prior to lifting the plants, they were watered copiously to ensure full hydration and all were checked for turgidity. Any plants showing signs of water stress, such as leaf rolling, were rejected. The plants were removed from their containers or, in the case of open ground material, dug up from the frames they were growing in and washed in a series of baths to remove all traces of soil. The root systems of all species, both lepidote and elepidote, reacted in a remarkably similar manner and no discernible differences in their ability to retain root fibre were observed during the washing exercise, despite this needing to be quite vigorous. It was interesting to note that extremely hygrophylous species such as Rhododendron hippophaeoides produced a notably larger mass of fine fibre. After four years of growth, tree-forming species such as Rhododendron calophytum had already developed a series of framework roots which in turn supported the fibrous feeding roots.

British Airways agreed to assist in the repatriation programme by providing sponsorship to enable David Paterson and Geng Yuying to travel to China in advance of the shipment of plants. The plants followed soon after having been transported to China by courier on a cargo plane. The hold temperature was within an acceptable range and therefore no special transit arrangements were necessary. Hua Xi Sub Alpine Botanic Garden provided the necessary import documents and the RBGE arranged for phytosanitary inspection and export documentation. The experience and advice of the courier company, DHL, also proved helpful. The shipment was routed from Edinburgh via London to Hong Kong and then onwards for customs clearance in Guangzhou. The shipment was delayed for two days in Guangzhou because of an unexplained discrepancy in the import permits. However, personal negotiations brought about the release of the shipment and arrangements were made to fly the plants to Chengdu where they were given a final phytosanitary check before being loaded into a jeep for the last leg of the journey to the Long Xi Reserve.

The plants arrived in good condition and all appeared to be reasonably turgid. Prior to planting, they were immersed in buckets of water for approximately two hours. This also enabled much of the vermiculite to be removed from the root fibre 
thus ensuring good contact with the soil when finally planted. The plants were planted in raised nursery beds that contained soil of similar properties to the media within which they had been grown in Edinburgh. Soil pH was measured at pH5.5 and was largely organic in content, being naturally peaty with a fibrous structure. Planting was carried out under ideal conditions of light rain with no wind. The plants were left uncovered for four weeks, during which time it rained on most days. The soil temperature, although gradually dropping, was still warm enough to allow root activity and after the four week period most of the plants remained turgid with no evidence of stress. Some species within the subgenus Hymenanthes, particularly members of subsections Glishcra and Barbata, showed signs of fungal attack to the stem and leaf petiole. This was due perhaps to trapped moisture during transit combined with superficial crushing of stem tissue during the lifting and preparation stages. Affected plants appeared to respond to treatment using an unknown fungicide supplied and applied by a local farmer. After one month and before the onset of winter, the plants were covered by a low polythene structure. The structure was erected in such a way as to enable routine inspection and watering of the plants.

Over the winter months a few plants died from what could best be described as transplant stress. Examination of their root systems revealed dieback of the fibre, and in the case of Rhododendron primuliflorum, splitting of the bark around the base of the stem. One plant of Rhododendron ririei succumbed to an attack of mildew while, fortuitously, a second plant survived. A couple of plants disappeared, presumed stolen, including a fine young specimen of Rhododendron sperabile var weihsiense.

Of the 230 plants, representing almost 100 species, more than $80 \%$ established successfully. For those that died the causes of death included drying out, pathogen attack and theft. In general however, the main causes of failure were physiological disorders arising from transplant stress. Despite the losses, the exercise was hailed as a success and the repatriated species provided an embryonic rhododendron collection for Hua Xi Sub Alpine Botanic Garden.

\section{Stabilisation Programmes}

Concurrent with the repatriation programme and, in part as a result of the training provided by the RBGE, staff from Hua Xi were able to start a series of species stabilisation programmes for Rhododendron davidii and $R$. calophytum, two endemics of the Long Xi Reserve. Field work to locate and collect seed of other endemics from Sichuan Province was also undertaken and included the search for Rhododendron zheguoense and $R$. balangense, amongst others. Small populations of all these species were located and seed-based propagation work leading to the production of several thousand plants was carried out. Stabilisation programmes for other Chinese Red Data Book plants growing in the Long Xi Reserve was also carried out and the RBGE played an important role in investigating techniques for breaking dormancy in seeds of Davidia involucrata. 


\section{GARDEN DESIGN}

Subsequent growth of the repatriated rhododendron species proved to be good under the ideal climatic conditions that prevail in the Long Xi Reserve, and discussions took place concerning the most appropriate display policy for the plants. The Curator of Hua Xi Sub Alpine Botanic Garden decided, with approval from his colleagues in the Chinese Academy of Sciences Institute of Botany in Beijing, to design a garden within Hua Xi dedicated to the repatriation of rhododendron species from Edinburgh to China. An important objective of this Garden was to demonstrate the value of international collaboration in securing the survival of species through joint conservation efforts. A central water feature was created along with a small network of footpaths that were laid to provide access. The entrance to the Garden was located across a small bridge that leads to an architecturally pleasing interpretation panel constructed from wood and stone. This panel describes the work carried out by RBGE and Hua Xi Sub Alpine Botanic Garden that resulted in the repatriation and raising of the plants in this area of the Garden. Pleasingly, it has proved to be one of the most frequently visited areas of the Hua Xi garden.

During the construction of the 'Back to China Garden', Central China TV filmed a short documentary that was broadcast nationally. This generated a number of visits from Government officials and raised the overall profile of the project. A number of direct benefits arose from Government recognition of the project. Particularly important was the provision of access for RBGE staff to the wilderness areas of Sichuan and other provinces of China to collect seed of rare and endangered plants. This has resulted in the rapid development of the most species-diverse rhododendron collection in China. Hua Xi Sub Alpine Botanic Garden probably now contains the largest collection of wild origin Chinese rhododendron species in cultivation in the world.

The repatriation process was repeated for Guizhou Botanic Garden but, largely due to a less successful staff training programme, subsequent plant losses were greater. Despite the higher losses, the programme was worthwhile and secured a good level of collaboration between institutes. The repatriated material made a small contribution to an interesting and established collection of rare plants from the lower elevations of the Huang Duan Shan region of southwest China.

\section{CONCLUSION}

The basic facilities within Hua Xi Sub Alpine Botanic Garden illustrate well the contribution that a small team of dedicated horticulturists and scientists that spend their days working in a challenging environment can make to conservation. As a result of their efforts they have created a garden of distinction that contains many of China's most valuable natural treasures. The RBGE was privileged to be involved in the development of Hua Xi Sub Alpine Botanic Garden and, as a result, has played a small but significant role in the repatriation and stabilisation of a number of rare rhododendron species. 